\title{
BMJ Open Population health bio-phenotypes in 11-12 year old children and their midlife parents: Growing Up in Australia's Child Health CheckPoint
}

\author{
Melissa Wake, ${ }^{\circledR 1,2,3}$ Susan A Clifford ${ }^{\oplus 1,2}$
}

To cite: Wake M, Clifford SA. Population health bio-phenotypes in 11-12 year old children and their midlife parents: Growing Up in Australia's Child Health CheckPoint. BMJ Open 2019;9:1-2. doi:10.1136/ bmjopen-2019-030833

Received 3 April 2019 Accepted 4 April 2019
Check for updates

(C) Author(s) (or their employer(s)) 2019. Re-use permitted under CC BY-NC. No commercial re-use. See rights and permissions. Published by BMJ.

${ }^{1}$ Murdoch Children's Research Institute, Parkville, Victoria, Australia

${ }^{2}$ Department of Paediatrics, The University of Melbourne, Parkville, Victoria, Australia ${ }^{3}$ Department of Paediatrics and The Liggins Institute, The University of Auckland, Auckland, New Zealand

Correspondence to Professor Melissa Wake; melissa.wake@mcri.edu.au

\section{ABSTRACT}

In an ambitious undertaking, Growing Up in Australia's Child Health CheckPoint streamlined and implemented wide-ranging population phenotypes and biosamples relevant to noncommunicable diseases in nearly 1900 parent-child dyads throughout Australia at child aged 11-12 years. This BMJ Open Special Issue describes the methodology, epidemiology and parent-child concordance of 14 of these phenotypes, spanning cardiovascular, respiratory, bone, kidney, hearing and language, body composition, metabolic profiles, telomere length, sleep, physical activity, snack choice and healthrelated quality of life. The Special Issue also includes a cohort summary and study methodology paper.

\section{PREFACE}

The new millennium sparked ambitious new birth cohorts around the world. One such study was Growing Up in Australia (also known as the Longitudinal Study of Australian Children, LSAC). Australia's only national child 'population-representative' study, LSAC—now celebrating its 15th birthday-has captured environmental, social, developmental, service and economic data biennially since 2004, when it recruited 5000 infants and 5000 4-5year olds. In size, content and intent, LSAC resembles other millennial cohorts such as the UK's Millenium Cohort Study and the Growing Up in Scotland, Ireland and New Zealand studies.

What sets LSAC apart is its recent standalone biophysical wave. The Child Health CheckPoint ushers in a new depth and breadth of cross-generational precision phenotyping and biosamples. Its first major tranche of multisystems data were released for use by all researchers in January 2019 (go to https://dataverse.ada.edu.au/dataverse/ lsac to access the datasets), with genetic, micronutrient, oral health and other data to accrue over the coming years.

In this Special Issue of BMJ Open, we describe the CheckPoint's methodology ${ }^{1}$ and outline the epidemiology and intergenerational concordance of 14 diverse sets of measurements taken simultaneously in nearly 1900 parent-child dyads at child age 11-12years. ${ }^{2-15}$ All are relevant to people's current and future health and in particular to the development of non-communicable diseases.

Why devote an entire Special Issue of BMJ Open to what may seem straightforward information? The simple answer is that these articles report information that researchers often seek, but rarely find, regarding measured phenotypes at the population level.

First, a vital step in population-based research is understanding the distributional properties of one's measures-not just of central tendency (mean, median, mode), but also the shapes of distributions and the proportions of individuals falling beyond various percentile values. This information helps to plan sample sizes, categorise variables, design analyses and interpret likely generalisability. Quantifying parent-child concordance may help in teasing out meaningful causal effects of environmental exposures.

Second, we describe each measure's methods for secondary data users' reference. Understanding what was done is vital to transparency and interpretation. Unfortunately, journal word limits typically preclude detail on protocol when reporting associational research or cohort profiles. This BMJ Open Special Issue provides a peer-reviewed opportunity for redress. Reporting our methods may support future prospective harmonisation, lack of which is one of the biggest barriers to creating a unified evidence base. It may also encourage others to believe that the impossible is possible: multiple precise phenotypic measures can be streamlined and simultaneously incorporated in 'field' settings.

Third, the findings are interesting. Examples include: 
- Carotid artery intima-media thickness, distensibility and elasticity show only minor parent-child concordance at child aged 11-12 years. ${ }^{2}$

- Conversely, cross-generational concordance in multiple vascular function markers is established early. ${ }^{3}$

- Australian parent-child concordance values for the microvasculature align with moderate polygenic heritability reported in smaller studies. ${ }^{4}$

- Mean lung volumes were larger, but airway size was smaller than international standards. ${ }^{5}$

- Bone geometry and density show strong parent-child concordance even before the period of peak adolescent bone deposition. ${ }^{6}$

- Albuminuria is common among Australian children and adults, which is of concern because it predicts risk for kidney and cardiovascular disease and mortality. ${ }^{7}$

- Our multiple measures of auditory and verbal systems provide important reference values, since they are rarely captured in population settings. ${ }^{8}$

- Cross-generational concordance across all measures of leanness and adiposity is already evident by late childhood. ${ }^{9}$

- We report distinct age-specific and sex-specific metabolic profiles, with concentrations and sex differences generally greater in adults than children ${ }^{10}$.

- Relative telomere length is shorter in adults than children, and modest parent-child concordance diminishes with increasing parent age. ${ }^{11}$

- While most parents and children show adequate sleep duration, poor-quality (low-efficiency) sleep is common. ${ }^{12}$

- More parents than children met physical activity guidelines, despite parents having lower mean activity counts, indicating a need to coordinate meaningful definitions across age groups. ${ }^{13}$

- Small parent-child concordance during a standardised 15-min 'snack break' could account for substantial annualised population gradients in energy, fat and sodium intake for $11-12$ year olds. ${ }^{14}$

- Parent-child concordance in health-related quality of life was small in this relatively healthy sample. ${ }^{15}$

In conclusion, we hope that this BMJ Open Special Issue will be widely used for reference, planning and the science it contains on a wide range of health, molecular and risk phenotypes in older children and their parents.

Acknowledgements The authors thank the LSAC and CheckPoint study participants, staff and students for their contributions. Research Electronic Data Capture (REDCap; www.project-redcap.org) tools were used in this study.

Contributors Both authors conceived, cowrote, read and approved the manuscript.

Funding This work was supported by the National Health and Medical Research Council (NHMRC) of Australia (Project Grants 1041352, 1109355), The Royal Children's Hospital Foundation (2014-241), the Murdoch Children's Research Institute (MCRI), The University of Melbourne, the National Heart Foundation of Australia (100660) and the Financial Markets Foundation for Children (2014055, 2016-310). MW was supported by the NHMRC (Senior Research Fellowship 1046518, Principal Research Fellowship 1160906) and Cure Kids New Zealand. The MCRI administered the research grants for the study and provided infrastructural support (IT and biospecimen management) to its staff and the study but played no role in the conduct or analysis of the trial. The Australian Department of Social Services played a role in study design; however, no other funding bodies had a role in the study design and conduct; data collection, management, analysis and interpretation; preparation, review or approval of the manuscript and decision to submit the manuscript for publication. Research at the MCRI is supported by the Victorian Government's Operational Infrastructure Support Program.

Competing interests All authors have completed the ICMJE uniform disclosure form at www.icmje.org/coi_disclosure.pdf and declare financial support as described in the funding section.

Patient consent for publication Not required.

Provenance and peer review Not commissioned; internally peer reviewed.

Data sharing statement The Longitudinal Study of Australian Children datasets and technical documents are available to researchers at no cost via a licence agreement. Data access requests are co-ordinated by the National Centre for Longitudinal Data. More information is available at https://dataverse.ada.edu.au/ dataverse/lsac.

Open access This is an open access article distributed in accordance with the Creative Commons Attribution Non Commercial (CC BY-NC 4.0) license, which permits others to distribute, remix, adapt, build upon this work non-commercially, and license their derivative works on different terms, provided the original work is properly cited, appropriate credit is given, any changes made indicated, and the use is non-commercial. See: http://creativecommons.org/licenses/by-nc/4.0/.

\section{REFERENCES}

1. Clifford SA, Davies S, Wake M, et al. Child Health CheckPoint: Cohort summary and methodology of a physical health and biospecimen module for the Longitudinal Study of Australian Children. BMJ Open 2019;9(suppl 3):3-22.

2. Liu RS, Dunn S, Grobler AC, et al. Carotid artery intima-media thickness, distensibility, and elasticity: Population epidemiology and concordance in Australian children aged 11-12 years and their parents. BMJ Open 2019;9(suppl 3):23-33.

3. Kahn FK, Wake M, Lycett K, et al. Vascular function and stiffness: Population epidemiology and concordance in Australian children aged 11-12 years and their parents. BMJ Open 2019;9(suppl 3): $34-43$.

4. Dascalu J, Liu M, Lycett K, et al. Retinal microvasculature: Population epidemiology and concordance in Australian children aged 11-12 years and their parents. BMJ Open 2019;9(suppl 3):44-52.

5. Welsh L, Kathriachchige G, Raheem T, et al. Lung function: Population epidemiology and concordance in Australian children aged 11-12 years and their parents. BMJ Open 2019;9(suppl 3):53-62

6. Vlok J, Simm PJ, Lycett K, et al. pQCT bone geometry and strength: Population epidemiology and concordance in Australian children aged 11-12 years and their parents. BMJ Open 2019;9(suppl 3):63-74.

7. Larkins NG, Kim S, Carlin JC, et al. Albuminuria: Population epidemiology and concordance in Australian children aged 11-12 years and their parents. BMJ Open 2019;9(suppl 3):75-84.

8. Smith J, Wang J, Grobler AC, et al. Hearing, speech reception, vocabulary and language: Population epidemiology and concordance in Australian children aged 11-12 years and their parents. BMJ Open 2019;9(suppl 3):85-94.

9. Clifford SA, Gillespie AN, Olds T, et al. Body composition: Population epidemiology and concordance in Australian children aged 11-12 years and their parents. BMJ Open 2019;9(suppl 3):95-105.

10. Ellul S, Wake M, Clifford SA, et al. Metabolomics: Population epidemiology and concordance in Austrailan children aged 11-12 years and their parents. BMJ Open 2019;9(suppl 3):106-17.

11. Nguyen MT, Lycett $K$, Vryer R, et al. Telomere length: Population epidemiology and concordance in Australian children aged 11-12 years and their parents. BMJ Open 2019;9(suppl 3):118-26.

12. Matricciani L, Fraysse F, Grobler AC, et al. Sleep: Population epidemiology and concordance in Australian children aged 11-12 years and their parents. BMJ Open 2019;9(suppl 3):127-35.

13. Fraysse F, Grobler AC, Muller J, et al. Physical activity and sedentary activity: Population epidemiology and concordance in Australian children aged 11-12 years and their parents. BMJ Open 2019;9(suppl 3):136-46.

14. Vivarini P, Kerr JA, Clifford SA, et al. Food choices: Concordance in Australian children aged 11-12 years and their parents. BMJ Open 2019;9(suppl 3):147-56.

15. Catchpool M, Gold L, Grobler AC, et al. Health-related quality of life: Population epidemiology and concordance in Australian children aged 11-12 years and their parents. BMJ Open 2019;9(suppl 3):157-64. 